\title{
Randomized Clinical Trial Assessing the Efficacy and Safety of Bromocriptine-QR when Added to Ongoing Thiazolidinedione Therapy in Patients with Type 2 Diabetes Mellitus
}

\author{
Hermes Florez ${ }^{1,2}$, Richard Scranton ${ }^{3}$, Wildon R. Farwell4,5, Ralph A. DeFronzo ${ }^{6}$, Michael Ezrokhi' ${ }^{3}$, J. Michael Gaziano ${ }^{4,5}$ and Anthony H.
} Cincotta $^{3 *}$

${ }^{1}$ Geriatric Research, Education and Clinical Center, and Medical and Research Services, Miami VA Healthcare System, Miami, FL, USA

${ }^{2}$ Departments of Medicine and Epidemiology \& Public Health, Divisions of Geriatric Medicine and Endocrinology, University of Miami Miller School of Medicine, Miami, FL, USA

${ }^{3}$ VeroScience LLC, Tiverton, RI, USA

${ }^{4}$ Massachusetts Veterans Epidemiology Research and Information Center, VA Boston Healthcare System, Boston, MA, USA

${ }^{5}$ Division of Aging, Department of Medicine, Brigham and Women's Hospital and Harvard Medical School, Boston, MA, USA

${ }^{6}$ Diabetes Division, University of Texas Health Science Center at San Antonio, USA

\begin{abstract}
Aims: To evaluate the glycemic control efficacy and cardio-metabolic safety of bromocriptine- quick release (Bromocriptine-QR) among subjects with type 2 diabetes who were taking a thiazolidinedione (TZD) at baseline.

Methods: A subgroup from the Cycloset Safety trial who were taking a TZD at baseline with or without another oral anti-diabetes medication were randomized to receive additional once daily (morning) bromocriptine-QR (1.6 - 4.8 $\mathrm{mg} /$ day) or placebo for up to 52 weeks. Glycemic efficacy analyses were based on intent to treat modified (ITTm) and evaluable per protocol (EPP) population using general linear model after adjusting for baseline covariates and stratified by $\mathrm{A} 1 \mathrm{C}$ level of $<7.5$ of $\geq 7.5$. The odds ratio of participants achieving $\mathrm{A} 1 \mathrm{C} \leq 7 \%$ were calculated. Similar analyses for safety were performed on weight and hypoglycemia.
\end{abstract}

Results: In this trial 495 subjects were taking a TZD at baseline and 122 also had a baseline $A 1 C$ of $\geq 7.5$. For subjects with an $\mathrm{A} 1 \mathrm{C}$ of $\geq 7.5$, bromocriptine-QR treatment led to significant reduction in $\mathrm{A} 1 \mathrm{C}$ (ITTm $-0.81 \%, \mathrm{p}=0.001$ and EPP $-0.91 \%, p=0.002$ ), fasting plasma glucose (ITTm $-21.5 \mathrm{mg} / \mathrm{dl}, \mathrm{p}=0.03$ and EPP $-20.5 \mathrm{mg} / \mathrm{dl}, \mathrm{p}=0.05$ ), and higher frequency achieving an $\mathrm{A} 1 \mathrm{C} \leq 7 \%(32.1 \%$ vs. $15.9 \%, \mathrm{p}=0.05)$ when compared with placebo. For subjects with a baseline A1C of $<7.5$, subjects randomized to bromocriptine-QR had a greater odds of having an A1C level of $\leq 7.0$ (OR $2.74,95 \%$ $\mathrm{Cl} 1.45,5.15 ; p=0.002$ ). Treatment with bromocriptine-QR had no adverse impact on weight or risk of hypoglycemia.

Conclusion: Daily morning bromocriptine-QR added to ongoing TZD treatment for uncontrolled type 2 diabetes improved glycemic control and was well tolerated.

Keywords: Bromocriptine-QR; Thiazolidinedione; Type 2 diabetes; Hemoglobin Alc

\section{Introduction}

Type 2 diabetes mellitus (T2DM) is characterized by defects in insulin sensitivity and insulin secretion [1]. Insulin resistance is manifested early in the natural history of the disease but glucose tolerance remains normal because of a compensatory increase in insulin secretion and hyperinsulinemia. With time, however, there is progressive beta cell failure leading to the development of impaired glucose tolerance and eventually overt T2DM $[2,3]$. Initial drug-induced improvement in glycemic control in patients with T2DM deteriorates over time requiring the use of additional antidiabetic medications with different modes of action [3]. There is now growing evidence that favors the use of interventions that improve insulin resistance and preserve beta cell function to treat T2DM [2-5]. Thiazolidinedione (TZD) therapy in patients with T2DM improves glycemic control both by augmenting beta cell function [6,7] and enhancing tissue sensitivity to insulin by acting as peroxisome proliferator-activated receptor (PPAR) gamma agonists in liver and muscle [8-10]. Nonetheless, the glycemic control often worsens over time if TZD therapy is initiated late in the course of the disease. The addition of agents that improve insulin sensitivity, via a different mechanism than the TZDs, may be beneficial in patients failing TZD therapy.

Animal studies indicate that reduced hypothalamic dopaminergic tone promotes insulin resistance and glucose intolerance [11-14].
Appropriately timed delivery of bromocriptine to the central nervous system has been shown to reduce insulin resistance and glucose intolerance [15]. A quick release formulation of bromocriptine (bromocriptine-QR), when given to T2DM subjects in the morning within 2 hours of waking, improves glycemic control primarily by reducing post-prandial glucose without raising post-prandial insulin levels suggesting enhanced postprandial responsiveness to insulin $[16,17]$. Bromocriptine-QR recently was approved by the US Food and Drug Administration (FDA) and is indicated as an adjunct to diet and exercise to improve glycemic control in adults with T2DM. As a centrally acting insulin sensitizer $[11,15]$ bromocriptine-QR may have synergistic effects when added to beta cell preserving agents/ peripherally acting insulin sensitizers such as TZDs. The overall safety, including cardiovascular outcomes, of bromocriptine-QR was assessed

${ }^{*}$ Corresponding author: Anthony $\mathrm{H}$. Cincotta $\mathrm{PhD}$, VeroScience LLC, Tiverton, RI, USA, E-mail: Anthony_Cincotta@veroscience.com

Received September 16, 2011; Accepted October 01, 2011; Published October 10, 2011

Citation: Florez H, Scranton R, Farwell WR, DeFronzo RA, Ezrokhi M, et al. (2011) Randomized Clinical Trial Assessing the Efficacy and Safety of BromocriptineQR when Added to Ongoing Thiazolidinedione Therapy in Patients with Type 2 Diabetes Mellitus. J Diabetes Metab 2:142. doi:10.4172/2155-6156.1000142

Copyright: ( $2011 \mathrm{Florez} \mathrm{H}$, et al. This is an open-access article distributed unde the terms of the Creative Commons Attribution License, which permits unrestricted use, distribution, and reproduction in any medium, provided the original author and source are credited. 
Citation: Florez H, Scranton R, Farwell WR, DeFronzo RA, Ezrokhi M, et al. (2011) Randomized Clinical Trial Assessing the Efficacy and Safety of Bromocriptine-QR when Added to Ongoing Thiazolidinedione Therapy in Patients with Type 2 Diabetes Mellitus. J Diabetes Metab 2:142. doi:10.4172/2155-6156.1000142

Page 2 of 8

in a one year randomized clinical trial [18]. In addition to the overall safety and cardiovascular risk evaluation, additional analyses were pre-specified to assess the impact of bromocriptine-QR compared to placebo on glycemic measures among subgroups of the total subject population [19]. The purpose of this post-hoc analysis is to evaluate the effect of bromocriptine-QR on glycemic control after 52 weeks of treatment among participants who at baseline were treated with TZDs (with or without another OAA).

\section{Participants and Methods}

\section{Study design-cycloset safety trial}

The Cycloset Safety Trial was a 52-week, double blind, double dummy, multicenter trial. After a two-week lead-in period subjects were randomized 2:1 to usual diabetes treatment plus once daily (morning) bromocriptine-QR or placebo. The key elements and aspects of this study protocol were published previously [20]. The Cycloset Safety Trial was designed to enroll a broad population of participants with T2DM. Eligible participants had T2DM for at least 6 months, were on a stable T2DM regimen for at least 30 days prior to randomization consisting of either diet only or up to 2 anti-diabetes agents (one or two oral T2DM agents; insulin alone; or insulin in combination with an oral diabetes agent), had an A1C level $\leq 10.0 \%$ and were between 30 and 80 years of age. Exclusion criteria included current chronic use of prescription sympathomimetic drugs, ergot alkaloid derivatives or abortive migraine medications; or clinically significant co-morbid conditions such as uncontrolled hypertension, New York Heart Classification III-IV congestive heart failure (class I-II were allowed in the study), advanced renal failure or cancer within the past five years (other than non-melanoma skin or non-metastatic prostate cancer).

The study was conducted at 74 sites across the U.S., including 19 Veterans Affairs (VA) hospitals and 55 non-VA centers. An independent data safety and monitoring board met quarterly and reviewed unblinded data. Overall study oversight was by a steering committee consisting of two academic principal study investigators, scientific members of the study sponsor, members responsible for site management coordination (Clinical Research Management Inc., Agawam, MA and Veterans Affairs Cooperative Studies Program Center, Boston, MA), and members of the data and statistical coordinating center (EVEREST Inc., Toronto, CA) and independent data safety and monitoring board.

After randomization, drug therapy was initiated with one $0.8 \mathrm{mg}$ bromocriptine-QR or placebo tablet and titrated at a rate of 1 tablet (active or matching placebo) per week until a maximal tolerated dose of at least 2 tablets $(1.6 \mathrm{mg} /$ day) or a maximum of 6 tablets $(4.8 \mathrm{mg}$ bromocriptine-QR) per day was achieved. After titration, subjects remained on their maximal daily dose for a total of 52 weeks from randomization. Subjects continued on their baseline T2DM agents during the first 3 months of the study but study investigators were allowed to alter the subjects' dosages to optimize T2DM control as deemed appropriate in accordance with the 2004 American Diabetes Association treatment recommendations [21]. After 3 months, dosage adjustments and alterations in the T2DM drug regimen (elimination or addition of another OAA) were allowed if deemed necessary but could not include additions that resulted in a final concomitant anti-diabetes regimen that exceed two OAA or insulin plus one oral agent. Two physicians blinded to treatment assignment determined whether or not study subjects changed accordingly their concomitant anti-diabetes medications. The study protocol was approved by the appropriate review boards for each site and all participants provided a written informed consent to participate. The study was performed in accordance with the Declaration of Helsinki.

\section{Participant selection criteria}

For this post-hoc analysis of bromocriptine-QR efficacy and safety, a subset of subjects of the total study population from the Cycloset Safety Trial was selected among those who at baseline were taking a TZD (alone or in combination with another OAA).

\section{Study Evaluations}

\section{Efficacy and safety assessments}

A1C and fasting plasma glucose were measured at weeks $0,12,24$, 36 and 52. Data on adverse experiences, physical examinations, vital signs and body weight were collected at each study visit. All adverse experiences were rated by investigators for intensity and relationship to study drug. All serious adverse events were independently adjudicated. Laboratory evaluations included blood chemistries, hematology and urinalysis which all were performed by a central laboratory using their standard operating procedures (ACM Laboratories, Rochester, NY).

\section{Statistical analyses}

The aim of this analysis was to evaluate the between group change from baseline to week 52 in A1C for those not adequately controlled on TZD therapy defined as a baseline $\mathrm{A} 1 \mathrm{C}$ of $\geq 7.5$ and the odds of having an $\mathrm{A} 1 \mathrm{C}$ of $\leq 7.0$ after 52 weeks for those subjects with a baseline $\mathrm{A} 1 \mathrm{C}$ of $<7.5$. Efficacy analyses were performed on the intent to treat population consisting of all randomized participants who received at least one dose of study drug and who had both a baseline and at least one postbaseline measurement (Intent to Treat Modified [ITTm] population). Rosiglitazone equivalent dosages were assigned for subjects treated with pioglitazone such that 2,4 , and $8 \mathrm{mg}$ of rosiglitazone equaled 15,30 , and $45 \mathrm{mg}$ of pioglitazone, respectively. The Chi Square test was used to test differences between categorical variables and general linear models were used to calculate the between group difference $(95 \%$ confidence interval (CI)) in $\mathrm{A} 1 \mathrm{C}$ and fasting glucose from baseline to week 52 for bromocriptine-QR. Analysis of changes in A1C was stratified by baseline $\mathrm{A} 1 \mathrm{C}$ of $<7.5$ and $\geq 7.5$ and were adjusted for baseline A1C as well as for age, race/ethnicity, presence of concurrent OAA, medication intensification (defined as an increase in the dose of OAA medication or the addition of another OAA; or addition of insulin during follow-up), baseline rosiglitazone equivalent dose and duration of T2DM. For subjects with $\mathrm{A} 1 \mathrm{C}$ of $\geq 7.5$, changes in $\mathrm{A} 1 \mathrm{C}$ were also stratified by the presence and absence of OAA intensification. The frequency of participants who achieved an $\mathrm{A} 1 \mathrm{C}$ of $\leq 7 \%$ was assessed using Chi Square test. Logistic regression was used to calculate the odds ratio $(95 \% \mathrm{CI})$ of achieving an $\mathrm{A} 1 \mathrm{C}$ of $\leq 7 \%$ among participants taking bromocriptine-QR compared to placebo while adjusting for the covariates described above. Missing values of A1C were handled using the last observation carried forward (LOCF) method.

Changes in body weight was assessed for the entire group and stratified by baseline A1C of $<7.5$ and $\geq 7.5$.

For subjects with a baseline A1C of $\geq 7.5$ the impact of therapy on glycemic control (A1C and fasting glucose) based on the above described methods was assessed on the pre-specified evaluable per protocol (EPP) population defined as those subjects who were at least $80 \%$ compliant with prescribed dosing of study drug and completed 52 weeks of the study without any major protocol violations during the trial. 
Citation: Florez H, Scranton R, Farwell WR, DeFronzo RA, Ezrokhi M, et al. (2011) Randomized Clinical Trial Assessing the Efficacy and Safety of Bromocriptine-QR when Added to Ongoing Thiazolidinedione Therapy in Patients with Type 2 Diabetes Mellitus. J Diabetes Metab 2:142. doi:10.4172/2155-6156.1000142

All statistical analyses were conducted using SAS software version 8.2 (Cary, NC).

\section{Results}

Of the 3070 subjects randomized 2:1 to bromocriptine QR or placebo in the Cycloset Safety Trial, 495 were taking a TZD at baseline. Of these 495,373 subjects had a baseline A1C $<7.5 \%$ (254 on bromocriptine-QR and 119 on placebo) and 122 subjects had a baseline A1C $\geq 7.5 \%$ (78 on bromocriptine-QR and 44 on placebo). Of the 495 participants, 190 (57\%) bromocriptine-QR and 117 (72\%) placebo subjects completed 52 weeks of treatment. Reasons for discontinuation of therapy included adverse events: $21 \%$ bromocriptine-QR, $13 \%$ placebo; withdrawal of consent: $11 \%$ bromocriptine-QR, $6 \%$ placebo; lost to follow up: $4 \%$ bromocriptine-QR, 3\% placebo; other: $2 \%$ bromocriptine-QR, $4 \%$ placebo; protocol deviation: $2 \%$ bromocriptine- $\mathrm{QR}, 1 \%$ placebo: and sponsor or PI decision: $2 \%$ bromocriptine-QR, $2 \%$ placebo.

Baseline demographic and clinical characteristics (Table 1) for 495 subjects stratified by baseline A1C $(\geq 7.5$ and $<7.5)$. Similar baseline A1C were observed in study participants taking bromocriptine-QR and placebo in both the $\geq 7.5$ baseline group $(8.2 \pm 0.6 \%$ vs. $8.4 \pm 0.7 \%$, respectively) and the $<7.5$ baseline group $(6.5 \pm 0.6 \%$ vs. $6.4 \pm 0.6 \%$ respectively). Among subjects with baseline $\mathrm{A} 1 \mathrm{C} \geq 7.5$, the majority of bromocriptine-QR treated participants $(83 \%)$ and placebo treated participants (82\%) were taking another OAA in addition to a TZD. More participants were taking rosiglitazone at baseline compared to pioglitazone in both treatment arms (71\% for bromocriptine-QR and $59 \%$ for placebo). The baseline rosiglitazone equivalent dose of TZD was similar in both groups $(5.3 \pm 2.3 \mathrm{mg}$ in the bromocriptine-QR arm vs. $5.9 \pm 2.2 \mathrm{mg}$ in the placebo arm).

\section{Glycemic control}

Overall when added to a TZD, bromocriptine-QR produced

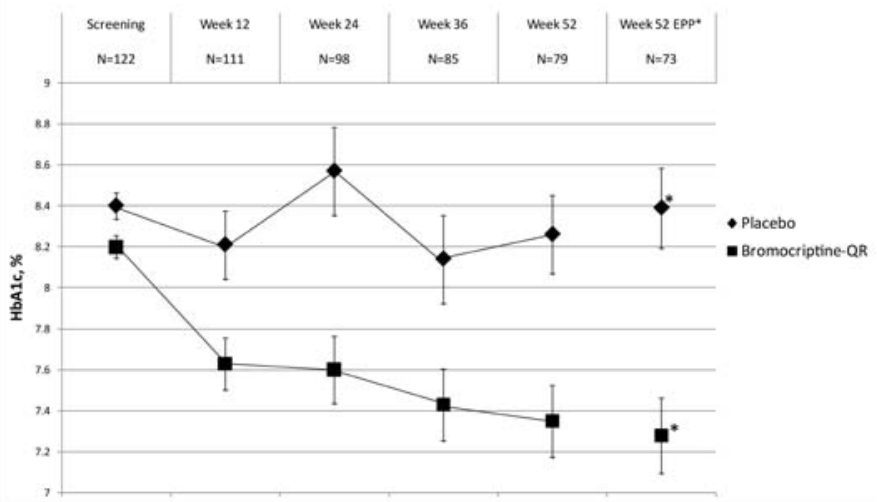

Figure 1: Change over time in percent $\mathrm{A} 1 \mathrm{C}$ by treatment group Among Subjects with a Baseline A1C of $\geq 7.5$. The average A1C for subjects receiving bromocriptine-QR (squares) and placebo (diamonds) are depicted at each study visit for subjects that had an $\mathrm{HbA} 1 \mathrm{c}$ measured. Overall there is a significant decline in $\mathrm{A} 1 \mathrm{C}$ for those subjects randomized to bromocriptineQR compared to no change after 52 weeks for those subjects randomized to placebo. EPP Analysis: Data represent those subjects completing 52 weeks of the study and being at least $80 \%$ compliant with prescribed dosing of study drug over the course of the trial. *The Week 52 EPP data point depicts the average $\mathrm{A} 1 \mathrm{C}$ after adjusting for baseline hemoglobin a1c, age, race/ ethnicity, presence of concurrent oral antihyperglycemic medication, change of antihyperglycemic medication during follow-up, baseline rosiglitazone equivalent dose, and duration of diabetes mellitus. The between group difference for change from baseline in A1C for bromocriptine-QR versus placebo subjects was $-0.91 \%(-1.47 \%,-0.35 \% ; p=0.002)$.

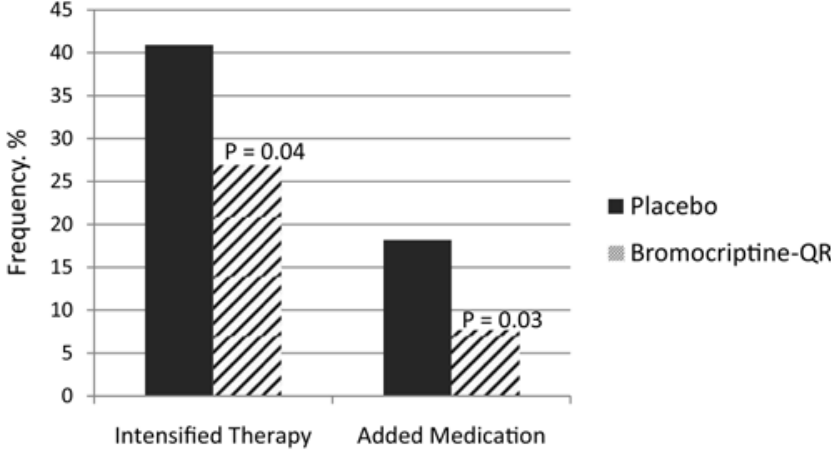

Figure 2: Antihyperglycemic medication changes during the course of the study by treatment group Among Subjects with a Baseline A1C of $\geq$ 7.5. Relative to participants randomized to bromocriptine-QR (solid bar), more participants randomized to placebo (striped bar) increased the dose of a concomitant oral antihyperglycemic agent (OAA); $41 \%$ versus $27 \%, \mathrm{P}=$ 0.04 or added a new OAA or insulin; $18 \%$ versus $8 \%, p=0.03$. Even though placebo-treated participants intensified their antihyperglycemic regimen more frequently, participants on bromocriptine-QR achieved better glycemic control over the 52 week treatment period.

significant improvements in glycemic control. For subjects with a baseline A1C level of $\geq 7.5$ the between group difference in change from baseline in A1C was significant. (Figure 1, Table 2). Using ITTm analysis, after controlling for baseline demographic and clinical characteristics, including baseline glycemic control and changes in concomitant OAA, the between group reduction (95\% CI) from baseline in $\mathrm{A} 1 \mathrm{C}$ was $-0.81 \%(-1.30 \%,-0.33 \%$; $\mathrm{p}=0.001)$ for participants randomized to bromocriptine-QR compared to placebo (Table 2) while for fasting plasma glucose was $-21.5 \mathrm{mg} / \mathrm{dl}(-41.0 \mathrm{mg} / \mathrm{dl},-1.9$ $\mathrm{mg} / \mathrm{dl} ; \mathrm{p}=0.03)$. Relative to participants randomized to bromocriptine$\mathrm{QR}$, more participants randomized to placebo increased the dose of a concomitant OAA ( $41 \%$ versus $27 \%, \mathrm{P}=0.04$ ) or added a new OAA or insulin ( $18 \%$ versus $8 \%, \mathrm{p}=0.03$ ) (Figure 2$)$. Even though placebotreated participants intensified their antihyperglycemic regimen more frequently, participants on bromocriptine-QR achieved better glycemic control over the 52 week treatment period. Stratified by intensification of therapy, the between group difference in A1C change was $-0.82 \%$ $(-1.47 \%,-0.18 \%)$ among participants who did not intensify therapy and $-0.96 \%(-1.76 \%,-0.16 \%)$ among participants who did intensify therapy. For fasting plasma glucose and stratified by intensification therapy, the reduction was $-23.5 \mathrm{mg} / \mathrm{dl}(-49.2 \mathrm{mg} / \mathrm{dl}, 2.1 \mathrm{mg} / \mathrm{dl})$ among participants who did not intensify therapy and $-28.6 \mathrm{mg} / \mathrm{dl}(-62.1 \mathrm{mg} / \mathrm{dl}, 5.0 \mathrm{mg} / \mathrm{dl})$ among participants who did intensify therapy. A greater percentage of participants achieved an A1C $\leq 7 \%$ with bromocriptine-QR (32.1\%) than with placebo $(15.9 \%)(\mathrm{P}=0.05)$. After controlling for the multiple covariates described herein, the odds ratio (95\% CI) of achieving a $\mathrm{A} 1 \mathrm{C} \leq 7 \%$ among participants taking bromocriptine-QR compared to placebo was $3.33(1.12,9.99)(\mathrm{p}=0.03)$.

The results of the intervention on $\mathrm{A} 1 \mathrm{C}$ and fasting glucose for the EPP analysis were similar to the ITTm analysis. In the fully adjusted model the between group difference for change from baseline in $\mathrm{A} 1 \mathrm{C}$ and fasting glucose levels for bromocriptine-QR versus placebo subjects were $-0.91 \%(-1.47 \%,-0.35 \% ; \mathrm{p}=0.002)$ and $-20.5 \mathrm{mg} / \mathrm{dl}(-41.1$ $\mathrm{mg} / \mathrm{dl}, 0.0 \mathrm{mg} / \mathrm{dl} ; \mathrm{p}=0.05)$, respectively.

Among subjects with an $\mathrm{A} 1 \mathrm{C}$ of $<7.5$, the change from baseline in A1C in the ITTm analysis for both groups was small (bromocriptineQR $0.14(0.04,0.24)$ vs. placebo $0.29(0.14,0.44)$ likely due to the low 
Citation: Florez H, Scranton R, Farwell WR, DeFronzo RA, Ezrokhi M, et al. (2011) Randomized Clinical Trial Assessing the Efficacy and Safety of Bromocriptine-QR when Added to Ongoing Thiazolidinedione Therapy in Patients with Type 2 Diabetes Mellitus. J Diabetes Metab 2:142. doi:10.4172/2155-6156.1000142

Page 4 of 8

\begin{tabular}{|c|c|c|c|c|}
\hline \multirow[b]{2}{*}{ Characteristics } & \multicolumn{2}{|l|}{ Baseline $\mathrm{A} 1 \mathrm{C} \geq 7.5$} & \multicolumn{2}{|l|}{ Baseline A1C $<7.5$} \\
\hline & $\begin{array}{l}\text { Bromocriptine-QR } \\
(\mathrm{N}=78)\end{array}$ & $\begin{array}{l}\text { Placebo } \\
(\mathrm{N}=44)\end{array}$ & $\begin{array}{l}\text { Bromocriptine-QR } \\
\mathrm{N}=254\end{array}$ & $\begin{array}{l}\text { Placebo } \\
\mathrm{N}=119\end{array}$ \\
\hline Age & $56.4 \pm 11.0$ & $59.6 \pm 10.9$ & $59.9 \pm 9.8$ & $58.7 \pm 10.3$ \\
\hline$\%$ Female & 52.6 & 43.2 & 57.5 & 24.0 \\
\hline $\begin{array}{c}\text { Race/Ethnicity } \\
\text { \% White } \\
\% \text { Black } \\
\text { \% Hispanic } \\
\text { \% Other }\end{array}$ & $\begin{array}{l}62.8 \\
16.9 \\
15.4 \\
3.8\end{array}$ & $\begin{array}{l}70.5 \\
9.1 \\
15.9 \\
4.5\end{array}$ & $\begin{array}{l}66.9 \\
16.9 \\
13.4 \\
2.8\end{array}$ & $\begin{array}{l}76.5 \\
14.3 \\
8.4 \\
0.8\end{array}$ \\
\hline Weight, kg & $94.4 \pm 19.4$ & $95.5 \pm 20.5$ & $94.3 \pm 17.3$ & $97.4 \pm 19.2$ \\
\hline Body Mass Index, $\mathrm{kg} / \mathrm{m}^{2}$ & $32.9 \pm 5.1$ & $32.7 \pm 5.2$ & $33.1 \pm 5.1$ & $33.6 \pm 4.8$ \\
\hline Duration of diabetes mellitus, years & $7.8 \pm 7.5$ & $9.3 \pm 7.6$ & $6.9 \pm 6.0$ & $6.2 \pm 4.2$ \\
\hline $\begin{array}{l}\text { Screening thiazolidinedione } \\
\text { \% Rosiglitazone } \\
\% \text { Pioglitazone }\end{array}$ & $\begin{array}{l}71.0 \\
29.0\end{array}$ & $\begin{array}{l}59.0 \\
41.0\end{array}$ & $\begin{array}{l}45.3 \\
54.7\end{array}$ & $\begin{array}{l}42.9 \\
57.1\end{array}$ \\
\hline Baseline Rosiglitazone Equivalent Dose, mg & $5.3 \pm 2.3$ & $5.9 \pm 2.2$ & $5.1 \pm 2.3$ & $5.4 \pm 2.4$ \\
\hline Hemoglobin $\mathrm{A}_{1 \mathrm{c}} \%$ & $8.2 \pm 0.6$ & $8.4 \pm 0.7$ & $6.5 \pm 0.6$ & $6.4 \pm 0.6$ \\
\hline Fasting plasma glucose, mg/dl & $172 \pm 39.7$ & $175 \pm 44.1$ & $125 \pm 25$ & $126 \pm 26$ \\
\hline Systolic Blood Pressure, $\mathrm{mmHg}$ & $129 \pm 13.4$ & $131 \pm 14.3$ & $129 \pm 14$ & $128 \pm 13$ \\
\hline $\begin{array}{l}\text { Diastolic Blood Pressure, } \mathrm{mmHg} \\
\text { Baseline Diabetic Therapy at Baseline }\end{array}$ & $76.9 \pm 7.9$ & $76.9 \pm 9.6$ & $77 \pm 8$ & $77 \pm 9$ \\
\hline $\begin{array}{l}\text { \% Taking thiazolidinedione only } \\
\% \text { Taking TZD with Metformin } \\
\% \text { Taking TZD with Sulfonylurea } \\
\% \text { Taking TZD with Other Oral Diabetes Med }\end{array}$ & $\begin{array}{l}17 \\
60 \\
22 \\
3\end{array}$ & $\begin{array}{l}18 \\
43 \\
39 \\
2.3\end{array}$ & $\begin{array}{l}37 \\
50 \\
14 \\
0.4\end{array}$ & $\begin{array}{l}40 \\
30 \\
4 \\
0.8\end{array}$ \\
\hline
\end{tabular}

Data presented as mean \pm standard deviation (unless otherwise specified)

Table 1: Baseline demographic and clinical characteristics of the study population.

Glycemic Control Parameter

\begin{tabular}{|c|c|c|}
\hline \multicolumn{3}{|c|}{ Glycemic Control Parameter } \\
\hline & HbA1c, \% (95\% Cl) & Fasting Plasma Glucose, $\mathrm{mg} / \mathrm{dl}(95 \% \mathrm{Cl})$ \\
\hline \multicolumn{3}{|c|}{ Adjusted for baseline glycemic measure $\dagger$} \\
\hline Bromocriptine-QR & $-0.62(-0.90,-0.34)$ & $-10.4(-21.9,1.1)$ \\
\hline Placebo & $0.04(-0.33,0.42)$ & $4.6(-10.7,19.9)$ \\
\hline Between group difference & $-0.66(-1.13,-0.19) ; p<0.01$ & $-15.0(-34.1,4.1) ; p=0.12$ \\
\hline \multicolumn{3}{|l|}{ Fully adjusted model } \\
\hline Bromocriptine-QR & $-0.67(-0.96,-0.39)$ & $-12.7(-24.1,-1.3)$ \\
\hline Placebo & $0.14(-0.24,0.52)$ & $8.7(-6.6,24.1)$ \\
\hline Between group difference & $-0.81(-1.30,-0.33) ; p=0.001$ & $-21.5(-41.0,-1.9) ; p=0.04$ \\
\hline
\end{tabular}

*ITTm analysis: modified intent to treat - all subjects treated that had one post randomization laboratory measure, missing week values of HbA1c and fasting plasma glucose were handled using the last observation carried forward method

†Adjusted for baseline glycemic measure: Model controlled for baseline HbA1c for the HbA1c outcome and for baseline Fasting Plasma Glucose for the Fasting Plasma Glucose outcome

fFully adjusted model: Model controlled for baseline glycemic measures (\% for HbA1c and mg/dL for fasting glucose), age (years), race/ethnicity (white, black, Hispanic, other), presence of concurrent oral antihyperglycemic medication (yes/no), whether the dose of antihyperglycemic medication was adjusted during follow-up (increase, decrease, same), whether additional antihyperglycemic medication was added during follow-up (yes/no), baseline rosiglitazone equivalent dose (mg), and the duration of diabetes mellitus (years)

Table 2: Effect of Bromocriptine-QR on Change from baseline to week 52 for HbA1c and Fasting Plasma Glucose (ITTm) among Subjects with Baseline A1c of $\geq 7.5^{\star}$.

average starting $\mathrm{A} 1 \mathrm{C}$ of 6.4 (Table 3). However a greater proportion of subjects on bromocriptine-QR (83\%) vs. placebo $(72 \%)$ met the $\mathrm{AlC}$ goal of $\leq 7.0$ at week 52 . The odds of meeting the ADA A1C goal of $\leq 7.0$ after 52 weeks adjusted for baseline A1C level and the fully adjusted model was greater for subjects that added bromocriptine-QR (OR 2.67; 95\% CI 1.46, 4.88; $\mathrm{p}=0.002$ and $2.74 ; 95 \%$ CI 1.45, 5.15; $\mathrm{p}=0.002$; respectively) as compared to placebo. Similar results were obtained for the EPP treatment population.

\section{Changes in weight}

At baseline there was no difference between the treatment groups in BMI in those with either A1C $\geq 7.5$ or $<7.5$ at baseline. Among all participants in the study, over the 52 week trial, there was no statistically significant difference in the between group change from baseline in weight for the EPP population that stayed on treatment after adjustment for baseline weight (bromocriptine-QR vs. placebo: -0.26 $\mathrm{kg}(-1.47$ to 0.95$) ; \mathrm{p}=0.68)$. In a subgroup analysis, among subjects with an $\mathrm{A} 1 \mathrm{C}$ of $\geq 7.5$ at baseline, the placebo arm experienced an increase in weight by $2.26 \mathrm{~kg}$ (95\% CI: 0.19 to $4.35 \mathrm{p}=0.03)$ whereas weight in the bromocriptine-QR participants did not change $(-0.22 \mathrm{~kg}, 95 \% \mathrm{CI}$ : -2.06 to $1.61 ; \mathrm{p}=0.81$ ). However the between group difference of -2.47 $\mathrm{kg}(95 \%$ CI: -5.23 to 0.29$)$ was not statistically significant $(\mathrm{p}=0.08)$. Similarly in an EPP population among subjects with an A1C of $<7.5$ at baseline between group difference of $0.25 \mathrm{~kg}$ ( $95 \% \mathrm{CI}$ : -1.08 to 1.58 ) was not statistically significant $(\mathrm{p}=0.7)$.

\section{Tolerability}

Among all study participants, common adverse events among 
Citation: Florez H, Scranton R, Farwell WR, DeFronzo RA, Ezrokhi M, et al. (2011) Randomized Clinical Trial Assessing the Efficacy and Safety of Bromocriptine-QR when Added to Ongoing Thiazolidinedione Therapy in Patients with Type 2 Diabetes Mellitus. J Diabetes Metab 2:142. doi:10.4172/2155-6156.1000142

Page 5 of 8

\begin{tabular}{|c|c|c|}
\hline Population & Adjusted Baseline A1C & Fully adjusted modelł \\
\hline Intent to Treat* & \multicolumn{2}{|c|}{ Change in A1C ( $95 \%$ confidence interval) } \\
\hline Bromocriptine-QR, N = 254 & $0.13(0.03,0.23)$ & $0.14(0.04,0.24)$ \\
\hline Placebo, $\mathrm{N}=119$ & $0.30(0.15,0.45)$ & $0.29(0.14,0.44)$ \\
\hline \multirow[t]{2}{*}{ Between group difference change from baseline in $\mathrm{A} 1 \mathrm{C}$} & $-0.17(-0.35,0.001) ; p=0.06$ & $-0.15(-0.33,0.002) ; p=0.09$ \\
\hline & \multicolumn{2}{|c|}{ Odds Ratio (95\% confidence interval) } \\
\hline A1C Goal of $\leq 7.0$ at week 52 & $2.67(1.46,4.88) ; p=0.002$ & $2.74(1.45,5.15) ; p=0.002$ \\
\hline Evaluable Per Protocol & \multicolumn{2}{|c|}{ Change in A1C (95\% confidence interval) } \\
\hline Bromocriptine-QR, N = 147 & $0.16(0.05,0.27)$ & $0.15(0.04,0.27)$ \\
\hline Placebo, $\mathrm{N}=85$ & $0.33(0.18,0.48)$ & $0.34(0.19,0.48)$ \\
\hline \multirow[t]{2}{*}{ Between group difference change from baseline in $\mathrm{A} 1 \mathrm{C}$} & $-0.17(-0.35,0.002) ; p=0.08$ & $-0.18(-0.37,0.001) ; p=0.06$ \\
\hline & \multicolumn{2}{|c|}{ Odds Ratio (95\% confidence interval) } \\
\hline A1C Goal of $\leq 7.0$ at week 52 & $2.40(1.17,4.90) ; p=0.02$ & $2.60(1.25,5.42) ; p=0.01$ \\
\hline
\end{tabular}

*ITTm analysis: modified intent to treat - all subjects treated that had one post randomization laboratory measure, missing week values of $\mathrm{A} 1 \mathrm{C}$ and fasting plasma glucose were handled using the last observation carried forward method

fFully adjusted model: Model controlled for baseline glycemic measures (\% for A1C and mg/dL for fasting glucose), age (years), race/ethnicity (white, black, Hispanic, other), presence of concurrent oral antihyperglycemic medication (yes/no), whether the dose of antihyperglycemic medication was adjusted during follow-up (increase, decrease, same), whether additional antihyperglycemic medication was added during follow-up (yes/no), baseline rosiglitazone equivalent dose (mg), and the duration of diabetes mellitus (years)

Table 3: Effect of Bromocriptine-QR on Change from baseline to week 52 for $\mathrm{HbA} 1 \mathrm{c}$ ands Odds of Meeting Goal A1C of $\leq 7.0 \mathrm{Among}$ Subjects with Baseline A1C of $<7.5$

those randomized to bromocriptine-QR that occurred at a rate of $\geq \mathrm{a}$ 2 percentage point difference from placebo included nausea (44\% vs. $7 \%)$, vomiting ( $9 \%$ vs. $1 \%$ ), fatigue ( $14 \%$ vs. $10 \%)$ and headache $(12 \%$ vs. 6\%). In contrast, events occurring less often with bromocriptineQR compared to placebo included weight gain (3\% vs. 5\%). Edema was similarly reported in both groups at $9 \%$. The discontinuation rate due to adverse events for bromocriptine-QR and placebo-treated subjects was $21 \%$ and $13 \%$, respectively. Fractures were reported equally in both groups at $3 \%$. There were seven events of hypoglycemia reported in the bromocriptine-QR arm, six among those with A1C $<7.5$, and one reported in the placebo arm with $A 1 C \geq 7.5$. None of the hypoglycemic events in the bromocriptine-QR-treated group were described as severe or serious. One event of hypoglycemia was reported in the placebo-treated group and was described as severe and serious. Implicating factors other than bromocriptine-QR were present among 5 of the subjects reporting hypoglycemia (1 subject had stopped bromocriptine-QR prior to the event, two subjects increased their sulfonylurea dose just prior to the event, another subject's event occurred upon increasing the bromocriptine-QR dose to 4 tablets per day so it was decreased to three without further hypoglycemic events and one subject had not eaten all morning).

\section{Safety}

Among all participants in the study, 26 subjects in the bromocriptine-QR treated group (7.8\%) reported 33 serious adverse events while the placebo-treated group had 13 subjects (7.9\%) reporting 14 serious adverse events. In the cardiac disorders body system class there were nine events (3\%) in the bromocriptine-QR group and seven $(4.3 \%)$ in the placebo group. No other body system classes had events occurring in greater than $2 \%$ of either group.

\section{Discussion}

Among participants with suboptimal glycemic control who were taking a TZD with or without another oral anti-diabetes medication, the addition of bromocriptine-QR resulted in a sustained improvement in A1C over 52 weeks of treatment. For subjects with a baseline A1C of $\geq 7.5$, the between group difference in change from baseline on $\mathrm{AlC}$ was significantly reduced for those subjects receiving bromocriptineQR (ITTm - $0.81 \%$ and EPP $-0.91 \%$ ) and three times as many subjects reached a goal A1C of $\leq 7.0$, after accounting for various baseline covariates and adjusting for the greater tendency of the placebo arm to intensify their diabetes regimen. Similarly, for subjects with a baseline A1C of $<7.5$, subjects were more likely to the meet the A1C goal of $\leq 7.0$ after 52 weeks when treated with bromocriptine-QR. Regardless of incoming AlC level, the addition of bromocriptine-QR safely improved overall glycemic control when compared to standard of care. Inasmuch as the majority of subjects (90\%) in this analysis were taking TZDs and another OAA medication at baseline, the findings described herein suggest that bromocriptine-QR elicits such effects in subjects on a TZD plus another OAA medication. There was no statistically significant increase in weight among participants who took a TZD and bromocriptine-QR and this combination was well tolerated.

Insulin resistance and beta cell dysfunction are the key contributors to the pathogenesis of T2DM $[2,22,23]$. Therapies that improve insulin resistance have been demonstrated to delay the progression of impaired glucose tolerance to overt T2DM [24,25] and delay the time to initiation of insulin therapy among participants with T2DM $[3,6,26]$. Current guidelines for T2DM treatment advocate a stepwise approach that relies mainly on the initial therapy with metformin and/ or sulfonylurea [27]. However, these therapies do not preserve beta cell function long term and glycemic control in T2DM patients treated with these therapies deteriorates over a few years [28-30]. An alternative approach would be to use a therapy or combination of therapies early in the course of T2DM that improve beta cell function and ameliorate insulin resistance [2]. TZDs reduce insulin resistance by modulating the activity of the nuclear receptor PPAR gamma [31]. Activation of these receptors imparts changes in genes that govern insulin signal transduction but such agonist use also improves pancreatic beta cell function in T2DM subjects [32,33]. Bromocriptine-QR has been shown to reduce postprandial hyperglycemia without raising insulin levels in T2DM subjects and to enhance tissue sensitivity to insulin $[16,17]$. The current findings suggest that the combination of a TZD (with or without another OAA) plus bromocriptine-QR may be an effective strategy of establishing long-lasting improvements in glycemic control in patients with T2DM. In light of the recent FDA and European Medicines Agency actions to either severely restrict or prohibit, respectively, the use of rosiglitazone in T2DM patients due to potential risk of untoward cardiovascular events, these considerations respecting the potential benefits of combination TZD-bromocriptineQR therapy are directed towards the TZD, pioglitazone. 
Citation: Florez H, Scranton R, Farwell WR, DeFronzo RA, Ezrokhi M, et al. (2011) Randomized Clinical Trial Assessing the Efficacy and Safety of Bromocriptine-QR when Added to Ongoing Thiazolidinedione Therapy in Patients with Type 2 Diabetes Mellitus. J Diabetes Metab 2:142. doi:10.4172/2155-6156.1000142

Page 6 of 8

The biological mechanism(s) by which bromocriptine-QR produced these nearly year-long effects on A1C level in subjects in poor glycemic control on TZDs (baseline A1C: 8.3) and late in the disease process (average duration of T2DM: 8.5 years at baseline) is (are) unknown. Although, the specific effect of combined TZDbromocriptine-QR therapy on fasting versus postprandial glucose metabolism was not investigated, the placebo-adjusted decline in fasting plasma glucose concentration $(-20.5 \mathrm{mg} / \mathrm{dl})$ clearly cannot explain the decrement in A1C (-0.91) among bromocriptine-QR treated subjects. Given the inherently different modes of action of these agents on beta cell function and insulin sensitivity $[6-15,34,35]$ their potential synergistic effects on glycemic control (via impacting fasting and postprandial hyperglycemia) are all plausible and further research is needed to delineate the biochemical/physiological nature of these additive benefits. From a theoretical standpoint, combination therapy early in the progression of T2DM with a TZD that augments beta cell function [6,7] plus bromocriptine-QR that improves postprandial glucose metabolism, apparently by improving insulin sensitivity $[16,17]$ may offer a means of producing long lasting improvements in postprandial glycemic control.

In the Cycloset Safety Trial, only fasting glucose levels and A1C levels were obtained as glycemic indicators. Previous studies with bromocriptine-QR have clearly demonstrated that morning administration of bromocriptine-QR produces significant improvements in post prandial glucose levels without raising insulin levels [43]. A therapeutic approach that reduces postprandial hyperglycemia may offer unique benefits to the treatment of T2DM. Elevation of postprandial glucose is independently associated with increased risk for cardiovascular events [36-38] and microvascular complications [39]. Targeting post-prandial hyperglycemia also appears to offer advantages over focusing solely on fasting hyperglycemia. In a meta-analysis, Hanefeld et al. [40] reported that use of an $\alpha$-glucosidase inhibitor which primarily reduces postprandial glucose among participants with T2DM was associated with reductions in cardiovascular events. Additionally, in the Cycloset Safety Trial, patients randomized to bromocriptine- $\mathrm{QR}$ vs. standard of care experienced a significant $40 \%$ relative risk reduction (hazard ratio 0.60 ; 95\% confidence interval 0.37-0.96) in the pre-specified, composite cardiovascular endpoint point with fewer subjects experiencing a CVD event over one year ( $1.8 \%$ vs. $3.2 \%$, respectively ) [18]. In a secondary prevention trial (PROactive), pioglitazone also has been shown to reduce cardiovascular events [41]. Therefore, the combination of these two insulin sensitizers that have different modes of action, exhibit a positive effect on postprandial hyperglycemia [16,42] and other cardiovascular risk factors such as postprandial dyslipidemia and inflammation $[10,16,17]$ and reduce cardiovascular events deserves further exploration in larger randomized trials.

The risk of hypoglycemia is low with the combination of a TZD and bromocriptine-QR because neither agent stimulates insulin secretion. Among participants taking a TZD, the occurrence of hypoglycemia was reported as mild and likely attributable to other drugs known to be associated with increased risk for hypoglycemia such as sulfonylurea therapy. Nausea was the most common adverse event reported among participants receiving bromocriptine-QR. There was no increase in weight when bromocriptine-QR was added to participants failing a TZD. Additional studies are warranted to assess if the combination of bromocriptine-QR plus a TZD would minimize the weight gain commonly observed with TZDs [10].

It is important to point out the limitations of the present study. First, the analysis is limited by the relatively small number of participants on
TZD therapy (495 out of 3070), in large part due to the fact that the majority of participants in the Cycloset Safety Trial were being treated with metformin and/or a sulfonylurea. Second, the current analysis required adjustments for covariates to fully observe the reported effect of the addition of bromocriptine-QR to participants failing a TZD. Third, the majority (90\%) of the subjects in this analysis were being treated at baseline with another OAA in addition to a TZD, so the true relative contributions and nature of the TZDs' and other OAAs' actions upon the mechanistic interactions with bromocriptine-QR to provide the results obtained and described herein cannot be assessed. Finally, a greater proportion of subjects discontinued treatment for reasons other than adverse events with bromocriptine-QR as compared to placebo. However, strengths of this study include that this study is more representative of a real world clinical setting and the unadjusted analysis demonstrates a statistically and clinically significant reduction in A1C among participants taking bromocriptine-QR compared to their usual care after one year of therapy. Additionally, even among subjects with baseline $\mathrm{A} 1 \mathrm{C}<7.5$, those treated with bromocriptine-QR were nearly 3 times more likely to met the ADA recommended A1C of $\leq 7.0$ after 52 weeks. To our knowledge this the first study of its size to assess the added benefit of maintaining ideal glycemic control among patients that on average were well controlled. Additional studies will need to be conducted to confirm whether or not the addition of bromocriptine earlier in the disease course or among subjects already at an $\mathrm{A1C}$ of 7.0 or less would result in a greater continued success of maintaining optimal control as compared to current standard practice. Future studies should also investigate whether a lower dose of pioglitazone and bromocriptine-QR therapies used in combination, (and possibly without other OAA on board), would result in prolonged glycemic control while minimizing common side effects such as nausea with bromocriptine-QR and edema and weight gain associated with TZDs.

\section{Conclusions}

When administered to patients taking a TZD with or without another OAA agent, bromocriptine-QR significantly improved glycemic control which persisted over one year of treatment. This combination was not associated with increased risk for peripheral edema or weight gain which is common among those treated with TZDs. Evaluation of the relative impact of this combination therapy on fasting and post-prandial glucose warrants further investigation to define the mechanism of action of combination therapy of bromocriptine-QR and a TZD on the physiologic defects responsible for T2DM. The findings of this study support a rationale to pursue additional investigations to evaluate the long term benefits of combination bromocriptine-QR/ TZD therapy when initiated early-on in the progression of T2DM.

\section{Acknowledgements}

The initial sponsor of the study was Pliva d.d (Zagreb, Croatia) and subsequently VeroScience LLC (Tiverton, RI). The sponsors were involved in the design, reporting plan and statistical analysis plan. A steering committee was responsible for study conduct, data collection and data analysis for the overal study. AC, EL, MG, RS, HF, RD, and WF participated in the analysis and review of data. The writing of this report and the decision to publish was the responsibility of the principle study investigators and the current sponsor. All safety endpoints were adjudicated by an independent three member committee.

Dr. Florez reports that he currently has federal funding from the Department of Health and Human Service, National Institutes of Health (NIDDK) and the VA (CSP) and has served as a consultant to Astrazeneca and Santarus. Dr. Scranton currently serves as the Chief Medical Officer for VeroScience. Dr. Farwell reports that he currently or in the past two years has received investigator-initiated federal funding from the Department of Defense and Veterans Administration and has served as consultants to VeroScience. Dr. Ezrokhi is a scientist at VeroScience. 
Citation: Florez H, Scranton R, Farwell WR, DeFronzo RA, Ezrokhi M, et al. (2011) Randomized Clinical Trial Assessing the Efficacy and Safety of Bromocriptine-QR when Added to Ongoing Thiazolidinedione Therapy in Patients with Type 2 Diabetes Mellitus. J Diabetes Metab 2:142. doi:10.4172/2155-6156.1000142

Dr. DeFronzo has received grants from Takeda and Amylin-Lilly, is a speaker for Amylin-Lilly, and is a consultant for Amylin-Lilly,Takeda, Novartis, BoehringerIngelheim, ISIS and VeroScience. Dr. Gaziano reports that he currently or in the past two years has received investigator-initiated federal funding from National Institutes of Health ( $\mathrm{NCl}, \mathrm{NHLBI}, \mathrm{NIA}, \mathrm{NEI})$ and the VA (CSP) and non-federal investigator initiated funding from Amgen and Pliva; has received research support in the form of pills and or packaging from Wyeth Pharmaceuticals; has received honoraria from Bayer and McNeil Consumer Products for speaking engagements. Dr. Cincotta is the Chief Science Officer of VeroScience. The authors would like to the thank Donna Cowan for her support in preparing the data for this manuscript.

\section{References}

1. Defronzo RA (2009) From the triumvirate to the ominous octet: a new paradigm for the treatment of type 2 diabetes mellitus. Banting Lecture. Diabetes 58: 773-795.

2. Weyer C, Bogardus C, Mott DM, Pratley RE (1999) The natural history of insulin secretory dysfunction and insulin resistance in the pathogenesis of type 2 diabetes mellitus. J Clin Invest 104: 787-794.

3. Matthews DR, Cull CA, Stratton IM, Holman RR, Turner RC (1998) UKPDS 26 Sulphonylurea failure in non-insulin-dependent diabetic patients over six years. UK Prospective Diabetes Study (UKPDS) Group. Diabet Med 15: 297-303.

4. Wajchenberg BL (2007) Beta-cell failure in diabetes and preservation by clinica treatment. Endocr Rev 28: 187-218.

5. Kahn SE, Haffner SM, Heise MA, Herman WH, Holman RR, et al. (2006) Glycemic durability of rosiglitazone, metformin, or glyburide monotherapy. N Engl J Med 355: 2427-2443.

6. Gastaldelli A, Ferrannini E, Miyazaki Y, Matsuda M, Mari A, et al. (2007) Thiazolidinediones improve beta-cell function in type 2 diabetic patients. Am J Physiol Endocrinol Metab. 292: E871-E883.

7. Bajaj M, Suraamornkul S, Pratipanawatr T, Hardies LJ, Pratipanawatr W, et al. (2003) Pioglitazone reduces hepatic fat content and augments splanchnic glucose uptake in patients with type 2 diabetes. Diabetes 52: 1364-1370.

8. Miyazaki Y, He H, Mandarino LJ, DeFronzo RA (2003) Rosiglitazone improves downstream insulin receptor signaling in type 2 diabetic patients. Diabetes 52 1943-1950.

9. Nawrocki AR, Rajala MW, Tomas E, Pajvani UB, Saha AK, et al. (2006) Mice lacking adiponectin show decreased hepatic insulin sensitivity and reduced responsiveness to peroxisome proliferator-activated receptor gamma agonists. J Biol Chem 281: 2654-2660.

10. Yki-Jarvinen H (2004) Thiazolidinediones. N Engl J Med 351: 1106-1118.

11. Cincotta AH (2002) Hypothalamic role in Insulin Resistance and insulin Resistance Syndrome in Insulin Resistance and Insulin Resistance Syndrome. In: Hansen B, Shafrir E, eds. Frontiers in Animal Diabetes Research. Taylor and Francis, London: 271-312.

12. Luo S, Luo J, Meier AH, Cincotta AH (1997) Dopaminergic neurotoxin administration to the area of the suprachiasmatic nuclei induces insulin resistance. Neuroreport 8: 3495-3499.

13. Luo S, Meier AH, Cincotta AH (1999) Bromocriptine reduces obesity, glucose intolerance and extracellular monoamine levels in the ventromedial hypothalamus of Syrian hamsters. Neiroendocrinology 68: 1-10.

14. Luo S, Luo J, Cincotta AH (1999) Chronic ventromedial hypothalamic infusion of norepinephrine and serotonin promotes insulin resistance and glucose intolerance. Neuroendocrinology 70: 460-465.

15. Luo S, Liang Y, Cincotta AH (1999) Intracerebroventricular administration of bromocriptine ameliorates the insulin-resistant/glucose-intolerant state in hamsters. Neuroendocrinology 69: 160-166.

16. Cincotta AH, Meier AH, Cincotta Jr M (1999) Bromocriptine improves glycaemic control and serum lipid profile in obese Type 2 diabetic subjects: a new approach in the treatment of diabetes. Expert Opin Investig Drugs 8: 1683-1707.

17. Pijl H, Ohashi S, Matsuda M, Miyazaki Y, Mahankali A, et al. (2000) Bromocriptine: a novel approach to the treatment of type 2 diabetes. Diabetes Care 23: 1154-1161.

18. Gaziano JM, Cincotta AH, O'Connor CM, Ezrokhi M, Rutty D et al. (2010) Randomized Clinical Trial of Quick Release-Bromocriptine among Patients with Type 2 Diabetes on Overall Safety and Cardiovascular Outcomes. Diabetes Care 33: 1503-1508.
19. Cincotta AH, Gaziano JM, Ezrokhi M, Scranton R (2008) Cycloset (QuickRelease Bromocriptine Mesylate), a novel centrally acting treatment for type 2 diabetes. Diabetologia 51(Suppl 1): S22

20. Scranton RE, Gaziano JM, Rutty D, Ezrokhi M, Cincotta A (2007) A randomized double-blind, placebo-controlled trial to assess safety and tolerability during treatment of type 2 diabetes with usual diabetes therapy and either Cycloset or placebo. BMC Endocr Disord 7: 3-9.

21. Standards of Medical Care in Diabetes. Diabetes Care 200427 (Suppl. 1): S15-S35.

22. Reaven GM (1998) Banting Lecture 1998. Role of insulin resistance in human disease. Diabetes 37: 1595-1607.

23. Kahn SE (2001) Clinical review 135: The importance of beta-cell failure in the development and progression of type 2 diabetes. J Clin Endocrinol Metab 86 : 4047-4058.

24. Gerstein HC, Yusuf S, Bosch J, Pogue J, Sheridan P, et al. (2006) Effect of rosiglitazone on the frequency of diabetes in patients with impaired glucose tolerance or impaired fasting glucose: a randomised controlled trial. Lancet 368: 1096-1105.

25. Knowler WC, Barrett-Connor E, Fowler SE, Hamman RF, Lachin JM, et al (2002) Reduction in the incidence of type 2 diabetes with lifestyle intervention or metformin. N Engl J Med. 346: 393-403.

26. Cook MN, Girman CJ, Stein PP, Alexander CM, Holman RR (2005) Glycemic control continues to deteriorate after sulfonylureas are added to metformin among patients with type 2 diabetes. Diabetes Care 28: 995-1000.

27. Nathan DM, Buse JB, Davidson MB, Ferrannini E, Holman RR, et al. (2009) Medical management of hyperglycemia in type 2 diabetes: a consensus algorithm for the initiation and adjustment of therapy: a consensus statement of the American Diabetes Association and the European Association for the Study of Diabetes. Diabetes Care 32: 193-203.

28. Effect of intensive blood-glucose control with metformin on complications in overweight patients with type 2 diabetes (UKPDS 34). UK Prospective Diabetes Study (UKPDS) Group (1998). Lancet 352: 854-865.

29. U.K. prospective diabetes study 16. Overview of 6 years' therapy of type diabetes: a progressive disease. U.K. Prospective Diabetes Study Group (1995). Diabetes 44: 1249-1258

30. Intensive blood-glucose control with sulphonylureas or insulin compared with conventional treatment and risk of complications in patients with type 2 diabetes (UKPDS 33). UK Prospective Diabetes Study (UKPDS) Group (1998) Lancet 352: 837-853.

31. Murphy GJ, Holder JC (2000) PPAR-gamma agonists: therapeutic role in diabetes, inflammation and cancer. Trends Pharmacol Sci 21: 469-474.

32. Zeender E, Maedler K, Bosco D, Berney T, Donath MY, et al. (2004) Pioglitazone and sodium salicylate protect human beta-cells against apoptosis and impaired function induced by glucose and interleukin-1beta. J Clin Endocrinol Metab 89: 5059-5066.

33. Diani AR, Sawada G, Wyse B, Murray FT, Khan M (2004) Pioglitazone preserves pancreatic islet structure and insulin secretory function in three murine models of type 2 diabetes. Am J Physiol Endocrinol Metab 286: E116-E122.

34. Liang Y, Lubkin M, Sheng H, Scislowski PWD, Cincotta AH (1998) Dopamine agonist treatment ameliorates hyperglycemia, hyperlipidemia, and the elevated basal insulin release from islets of ob/ob mice. Biochimica et Biophysica Acta 1405: 1-13.

35. Liang $Y$, Jetton TL, Lubkin M, Meier AH, Cincotta AH (1998) Bromocriptine/ SKF38393 ameliorates islet dysfunction in the diabetic ( $\mathrm{db} / \mathrm{db})$ mouse. Cellular and Molecular Life Sciences 54: 703-711.

36. Sorkin JD, Muller DC, Fleg JL, Andres R (2005) The relation of fasting and 2-h postchallenge plasma glucose concentrations to mortality: data from the Baltimore Longitudinal Study of Aging with a critical review of the literature. Diabetes Care 28: 2626-2632.

37. Levitan EB, Song Y, Ford ES, Liu S (2004) Is nondiabetic hyperglycemia a risk factor for cardiovascular disease? A meta-analysis of prospective studies. Arch Intern Med 164: 2147-2155.

38. DECODE Study Group, the European Diabetes Epidemiology Group (2001) Glucose tolerance and cardiovascular mortality: comparison of fasting and 2-hour diagnostic criteria. Arch Intern Med 161: 397-405. 
Citation: Florez H, Scranton R, Farwell WR, DeFronzo RA, Ezrokhi M, et al. (2011) Randomized Clinical Trial Assessing the Efficacy and Safety of Bromocriptine-QR when Added to Ongoing Thiazolidinedione Therapy in Patients with Type 2 Diabetes Mellitus. J Diabetes Metab 2:142. doi:10.4172/2155-6156.1000142

Page 8 of 8

39. Shiraiwa T, Kaneto H, Miyatsuka T, Kato K, Yamamoto K, et al. (2005) Postprandial hyperglycemia is an important predictor of the incidence of diabetic microangiopathy in Japanese type 2 diabetic patients. Biochem Biophys Res Commun 336: 339-345.

40. Hanefeld M, Cagatay M, Petrowitsch T, Neuser D, Petzinna D, et al. (2004) Acarbose reduces the risk for myocardial infarction in type 2 diabetic patients: meta-analysis of seven long-term studies. Eur Heart J 25: 10-16.

41. Pratley RE (2006) The PROactive Study: pioglitazone in the secondary prevention of macrovascular events in patients with type 2 diabetes. Curr Diab Rep 6: 45-46.

42. Gastaldelli A, Casolaro A, Pettiti M, Nanniperi M, Ciociaro D, et al. (2007) Effect of pioglitazone on the metabolic and hormonal response to a mixed meal in type II diabetes. Clin Pharmacol Ther 81: 205-212.

43. Scranton R, Cincotta A (2010) Bromocriptine--unique formulation of a dopamine agonist for the treatment of type 2 diabetes. Expert Opin Pharmacother 11 269-79. 